\title{
Ameliyat Sırası Dönemde Kaliteli Hemşirelik Bakımına Ulaşmada Hemşirenin Rolü
}

\author{
Nursing Role to Reach Quality Nursing Care in the Intraoperatif Period
}

\author{
Semra EYI' $\dot{I}^{1}$ Nevin KANAN ${ }^{2}$, Neriman AKYOLCU ${ }^{3}$
}

İletişim/ Correspondence: Semra EYİ Adres/Address: Trakya Üniversitesi Keşan Hakkı Yörük Sağlık Yüksekokulu, Keşan/ Edirne Tel: 028471255 05-1138 Fax: 02847125506 Email: semra_il@yahoo.com

\begin{abstract}
$\ddot{O} Z$
Hemşirelik ve bakım, birbiriyle çok yakın iliş̧kisi olan iki kavramdır. "Bakım” etik bir çerçeve içerisinde, üzerinde hemşireliğin inşa edilmiş olduğu bir platform ve odak noktası olmuştur. Ameliyathane hemşireliği uygulamalarında bakımın temelini, ameliyathane hemşiresinin, girişim geçiren hastaların bireysel gereksinimlerini teorik ve uygulama bilgisini kullanarak karşılaması oluşturur. Bireyin/hastanın yaşamının her aşamasında olduğu gibi ameliyat sırası dönemde de gereksinimlerinin belirlenmesi ve uygun bakımın sağlanması, hemşirelik sürecinin önemli bir bölümünü oluşturur. Ameliyat sirası dönemde hemşirelik bakımi, hastanin güvenliğini ve homeostazisi sürdürmeye, hastaya uygun pozisyon vermeye ve psikolojik destek olmaya odaklanir. Ameliyat sirası dönemde hemşire, hastanin ağrl ve vücut sicaklığl yönetiminden, hastaya uygun pozisyon vermeden, hastayl bilgilendirmeden, hastaya psikolojik destek sağlayarak güvenli çevrenin oluşturulmasindan sorumludur. Fizyolojik bir varlık olarak insanın, yaşamın devamlılığını sürdürebilmesi için, temel gereksinimlerinin karşılanması gerekmektedir. Hemşirelik uygulamalarının amacı insana yardım etmektir. Sağllk hizmetlerinde yaşamsal önem taşıyan tüm alanlarda hataları azaltmak ve ortadan kaldırmak amacıyla kalite güvenliği programları kullanılmaktadır. Ameliyat sırası dönemde hasta gereksinimlerini belirleyip; hemşirelik süreci çerçevesinde, hemşirelik rolleri ile hasta hedeflerini ve sonuçlarını düzenleyen risk yönetimini ele alıp, hemşirelik bakımını uygulamak, sonuçta kaliteli bakıma ve hasta memnuniyetine ulaşmada bir yol olabilir. Bu düşüncelerle yola çıkılan bu çalışma, ameliyathane hemşirelerine kaliteli bakım ve hasta memnuniyetine ulaşmalarında izleyecekleri yol gösterici bir araç olması amacıyla yapılmıştır.
\end{abstract}

Anahtar Kelimeler: Ameliyat sırası dönem, kaliteli bakım, ameliyat sırası uygulamalar.

\section{ABSTRACT}

Nursing and care are two concepts which have close relation with one another. Providing the individual needs of patients by nurse that uses theoretical and practical knowledge constitutes the basis of care in nursing practice. As in every stage of patient's life after surgery, identifiying of Individual/Patient's needs and ensuring appropriate care in intraoperative period is an important part of nursing process. In the intraoperative period, the nurse is responsible for patient's pain and body temperature management, giving proper position, informing the patient, creation of a safe environment by providing psychological support to the patient. The human is a physiological entity thereupon it is neccesary to meet the basic human needs. Goal of Nursing practice is to help people. In all crucial areas of health services, quality assurance programs are used to eliminate and annihilate failures. In the intraoperative period, identifying patient's needs, implementing nursing care taking over risk management that regulates patient's goals and results in the framework of nursing process can be a way to achieve the quality of care and patient satisfaction in conclusion. This study has been compiled as a advisor for operating room nurses in order to reach the quality of care and patient satisfaction.

Keywords: Intraoperative period, the quality of care, intraoperative applications.

${ }^{1}$ Yrd. Doç. Dr. Trakya Üniversitesi Keşan Hakk Yörük Sağllk Yüksekokulu Edirne/ TURKEY, ${ }^{2}$ Prof. Dr. İstanbul Üniversitesi Florence Nightingale Hemşirelik Fakültesi, İstanbul/ TURKEY, ${ }^{3}$ Prof. Dr. İstanbul Üniversitesi Florence Nightingale Hemşirelik Fakültesi, İstanbul/ TURKEY.

Yazının gönderilme tarihi: 08.02.2016

Yazının basım için kabul tarihi: 11.04 .2017

doi: 10.17672/fnhd.67606 


\section{GíRiş}

Ameliyathane hemşiresi, hastanın ameliyathanede bulunduğu zaman içerisindeki bakımından sorumludur ve ameliyathane içinde koordinasyonu sağlar (Kanan ve Atilla 2002). Ameliyathane hemşiresi, temel yaşam gereksinimlerinin son derece önemli olarak ele alınd1ğ tıbbi ve cerrahi ilkelere göre belirlendiği bir ortamda çalışmakta; fizyolojik değişimler geçirdiği bilinen ya da tahmin edilen hastaların bakımından sorumlu olmaktadır. Sağlık ekibinin diğer üyeleri ile işbirliği içindeki ameliyathane hemşiresi, hastanın cerrahi girişim sürecinin tüm basamaklarında, bakım protokolünün planlanmasına kadar bakımın sürekliliğini garanti eder. Amerikan Ameliyathane Hemşireleri Derneği (AORN) tarafindan yapılan tanımda ameliyathane hemşiresi "ameliyat" ya da invaziv girişim nedeniyle potansiyel olarak koruyucu refleksleri ya da kendine bakım yetisi tehlikeye giren hastaların gereksinimlerini karşılamak üzere hemşirelik sürecini kullanarak bakımı belirleyen, koordine eden ve veren profesyonel hemşiredir" (Uludoğan 2010).

Ameliyathane hemşiresi kişinin güvenliğgi, mahremiyeti ve psikolojik durumu üzerine temellendirilen gereksinimlerini karşılamakla yükümlüdür. Ameliyat ve diğer invaziv işlemler uygulanan hastaların bakımında birincil sorumluluğa sahip olan ameliyathane hemşiresi, bireysel hasta gereksinimlerini karşılamak, etkili ve kaliteli bir hizmet verebilmek amaciyla hemşirelik bakımını planlayarak uygular. Diğer sağlık ekibi üyeleriyle işbirliği yaparak hasta bakımında sürekliliği sağlar. Ameliyathane hemşireliği etkinlikleri, yüksek riskli durumlardan hastaları korumak, fiziksel çevre güvenliğini sağlamak, hastanın fiziksel emosyonel, kültürel, etik ve dini gereksinimlerini karşılamak ve kişisel saygınlığını sürdürmesine yardım etmeyi içerir (Nicolette 1996; Kaymakçı 2005; Laden 1999; McGarvey, Chambers ve Boore 2000).

Ameliyathane hemşiresinin rollerinin analizinde çeşitli yaklaşımlar kullanılmıştır. Araştırmacıların, hasta, çevre ve tıbbi/ teknik işlerle ilgili rolleri, bağımlı, bağımsız rolleri tanımlamada rol bileşenlerini ele alma eğiliminde oldukları görülmüştür (McGarvey ve ark. 2000).

"Ameliyat sırası dönem” cerrahi girişim sırasındaki süreci belirtir. Cerrahi girişim sırasında hastanın güvenliğini ve konforunu sağlayan, cerrahi girişimi uygulayan, yaşamsal fonksiyonları sürdüren ve takip eden, verilen bakımı kaydetmeyi sağlayan, sağlık bakım ekibi tarafından yapılan aktiviteleri içerir. Cerrahi girişimin gerçekleştirilmesini kapsayan bu dönem, hastanın ameliyathane girmesiyle başlar, anestezi indüksiyonundan, hastanın ayılma odası veya yoğun bakıma nakledilmesine kadar sürer (Özbayır 2010).

\section{Ameliyat Sirası (Intraoperatif) Dönemde Bakım Öncelikleri}

- Anestezi indüksiyonu sırasında hastanın desteklenmesi

- Yaralanmayı önlemek ve cerrahi erişim sağlamak için güvenli hasta konumlandırma

- İşleme başlamadan önce duraklatmak için tüm ekip için bir "zaman aşımı” süreci oluşturulması ve aşağıdakilerin onaylanması;

- Doğru hasta kimliği,

- Doğru taraf,

- Yapılacak işlemin anlaşılır olması,

- Hasta onam formunun kontrol edilmesi,

- Doğru pozisyon verilmesi,

- Durumu uygun olarak doğru implantlar,

- Uygun mevcudiyetli x-1şınları,

- Enfeksiyonu önlemek için uygun cilt hazırlığı başlatılması,

- İşlem sırasında asepsinin sürdürülmesi,

- Uygun aralıklarla araç ve keskin sayımı tamamlanmas1,

- Tahmini riske dayalı yangın önleme tedbirlerinin uygulanmas1,

- İlgili güvenlik ve enfeksiyon kontrol önlemleri ve ameliyat süresi çerçeveleri de dahil olmak üzere, prosedürün dikkatle belgelenmesidir (Cohen 2007).

Ameliyathanede çalışan hemşireler hasta bakımı konusunda uzmanlaşmış bir rol oynar. Anestezi yönetiminin bir sonucu olarak kendilerini savunması müm- 
Tablo 1. Ameliyat Sırası (İntraoperatif) Dönemde Hipotermiyi Önlemede Hemşirenin Rolü

\begin{tabular}{|c|}
\hline HIPOTERMI \\
\hline Tanım: Beden $1 \mathrm{~s} 1 \mathrm{~s} 135.5^{\circ} \mathrm{C}$ nin altında \\
\hline Riskler \\
\hline 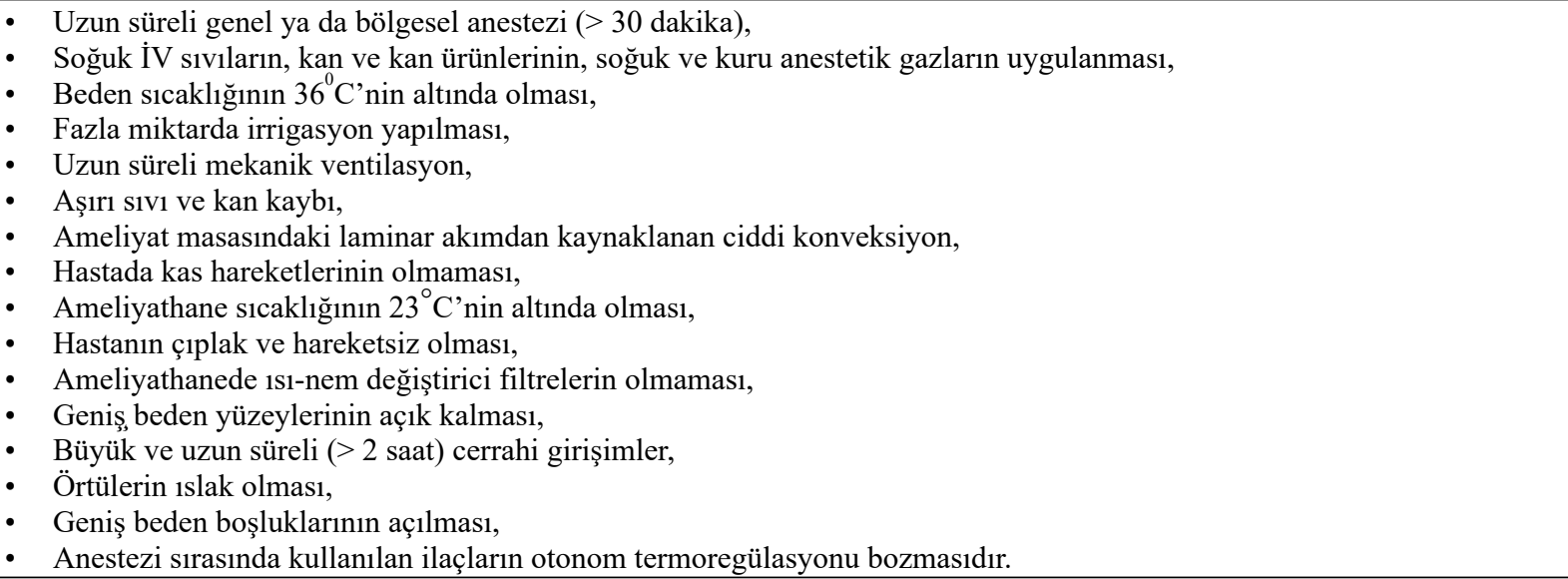 \\
\hline Komplikasyonlar \\
\hline $\begin{array}{l}\text { - Anestetik ilaçların etkisinin uzaması, } \\
\text { - Solunum ve kardiyovasküler sistem depresyonu, } \\
\text { - İlaç metabolizmasının yavaşlaması sonucu hasta derlenme süresinin uzaması ve metobolik bozuklukların ortaya çıkması, } \\
\text { - } \quad \text { Kara yeri iyileşmesinde gecikme ve cerrahi alan enfeksiyonunda artış, } \\
\text { - } \quad \text { Haagülopati, } \\
\end{array}$ \\
\hline
\end{tabular}

\section{Uygulanabilecek Girişimler}

- Ameliyathanede ortam sıcaklığı oda sıcaklığında olmalı (Minimum $20-25^{\circ} \mathrm{C}$ ) ve merkezi sıcaklık aktif ve pasif 1 sıtma yöntemleri ile korunmalı,

- Ameliyathane sıcaklığını artırmak cerrahi ekipte cilt ve göz kuruluğu gibi sorunlara neden oluyorsa nem oranı artırılmalı, gerekirse cerrahi ekibe soğutucu cihazlar sağlanmalı,

- Ameliyathanenin sıcaklığı ve nemi düzenli aralıklarla izlenmeli ve kaydedilmeli,

- Hastanın beden sıcaklığı ameliyat bitene kadar her $30 \mathrm{dk}$. da bir ölçülmeli, anestezi uygulamasından 30 dakika önce ve anesteziden 15 dakika sonra beden sıcaklığının $36^{\circ} \mathrm{C}$ 'nin altında olması durumunda anestezi uygulamasına başlanmamalı,

- Hasta da tanımlayıcı özellik olarak soğuk deri, solukluk, titreme (hafif), mental konfüzyon, uyuşukluk, huzursuzluk, solunum ve nabız hızında azalma belirtileri izlenmeli,

- Dehidratasyon bulguları ve hareketsizliğe bağlı dolaşımda azalma belirtileri gözlemlenmeli,

- Cerrahi alan dışında açık kalan beden bölümler steriliteye dikkat edilerek örtülmeli (Cerrahi girişim bölgesini etkilemiyorsa çorap, iç çamaşırı, şapka giydirilmeli),

- Anestezinin etkisinin 30 dakikadan daha uzun sürmesi beklenen tüm durumlarda, indüksiyondan sonra sicak hava üflemeli bir 1sitıcı (FAW) kullanılmalı ve bu 1 sitıcı en az $38^{\circ} \mathrm{C}^{\prime}$ ye ayarlanmalı,

- Sıcak hava üflemeli ısıtma ile saatlik $0.1-0.75^{\circ} \mathrm{C}^{\prime}$ lik 1 sıtma sağladığından ısıtma işlemine cerrahi girişim öncesinde başlanıp, cerrahi girişim sırası ve sonrası dönemde de devam edilmeli,

- Merkezi sıcaklık düşüşünü önlemek amacıyla anestetik gazlar, cerrahi girişim öncesi cilt hazırlığında kullanılacak antiseptikler, IV sıvılar, irrigasyon sıvıları, kan ve kan ürünleri hasta bireye uygulanmadan önce 1sitılmalı (Uygulanan tüm intravenöz sıvılar en az $37^{\circ} \mathrm{C}$ 'ye, sıvı miktarı fazla ise $42^{\circ} \mathrm{C}$ 'ye; irrigasyon sıvıları $40^{\circ} \mathrm{C}$ 'ye 1sıtılarak uygulanmalıdır. Isıtma işlemi özel cihazlarla yapılmalı, mikrodalga gibi cihazların kullanımından kaçınılmalıdır. Ancak kristalloid özellikteki sıvıların ısıtılmasında mikrodalga kullanımı güvenli, hızlı ve maliyet etkin bir yöntemdir),

- Anestezi uygulaması öncesi ekstremiteler 1sıtılmalı. Özel örtüler ile kapatılan ekstremiteler, 30-40 mmHg'lik negatif basınçla $44-46^{\circ} \mathrm{C}$ 'ye kadar 1 sıtılmış battaniyeler ile 1 sıtılabilir. Beden sıcaklığ $137^{\circ} \mathrm{C}$ ve üzerine çıtı̆̆ında aktif 1 sitmaya son verilmeli,

- Ameliyathanede ortam sıcaklığı oda sıcaklığında olmalı (Minimum 20-25을 ve merkezi sıcaklık aktif ve pasif 1 sıtma yöntemleri ile korunmalı.

Kaynak: AST 2015; Burns, Wojnakowski, Piotrowski ve Caraffa 2009; Closs, Macdonald, Hawthorn 1986; Ellis-Stoll, Anderson, Cantu, Englert, Carlile 1996; Erickson ve Yount 1991; Heidenreich ve Giuffre 1990, Heidenreich, Giuffre ve Doorley 1992; Hind, 1994; NIH 2008, Roizen, Sohn, L’Hommedieu, Wylie ve Ota 1980; TARD 2013; Vartiainen, Vuorio, Halonen, Hakola 1995; van Wijk ve Smalhout 1990; Yüksel ve Altun-Uğraş 2016. 
kün olmayan hastaları savunur. Ameliyat sırası dönemde hemşirelik bakımı, hastanın güvenliğini ve homeostazisi sürdürme, hastaya uygun pozisyon verme ve psikolojik destek olmaya odaklanır (Özbayır 2010).

$\mathrm{Bu}$ bağlamda ameliyat sırası dönemde hemşire hastanın ağrı ve beden sıcaklığı yönetiminden, hastaya uygun pozisyon vermeden, hastayı bilgilendirmeden, hastaya psikolojik destek sağlayarak güvenli çevrenin oluşturulmasından sorumludur. $\mathrm{Bu}$ düşüncelerle yola çıkılan bu çalışma, ameliyat sırası dönemde kaliteli bakıma ulaşmada ameliyathane hemşirelerinin rollerine ilişkin izleyecekleri yol gösterici bir araç olması amacıyla yapılmıştır.

Tablo 2. Ameliyat Sırası (İntraoperatif) Dönemde Normotermiyi Korumada Hemşirenin Rolü

\begin{tabular}{|l|}
\hline \multicolumn{1}{|c|}{ NORMOTERMI } \\
\hline Tanım: Beden 1 sısı $36^{\circ} \mathrm{C}-37.7^{\circ} \mathrm{C}$ arasında \\
\hline - Ameliyathanenin sıcaklığı ve nemi düzenli aralıklarla izlenmeli ve kaydedilmelidir, \\
- $\quad$ Ameliyat süresi boyunca hastaya üşüyüp üşümediği sorulmalıdır, \\
- Titreme, el ve ayaklarda üşüme/sıcaklık artışı belirtileri izlenmelidir. \\
\hline
\end{tabular}

Kaynak: AST 2015; Closs ve ark. 1986; Erickson ve Yount 1991; Hind 1994; Roizen ve ark. 1980, TARD 2013; van Wijk ve Smalhout 1990; Vartiainen ve ark. 1995.

Tablo 3. Ameliyat Sırası (İntraoperatif) Dönemde Hipertermiyi Önlemede Hemşirenin Rolü

\begin{tabular}{|c|}
\hline HIPERTERMI \\
\hline ק \\
\hline Riskler \\
\hline $\begin{array}{l}\text { - } \quad \text { Kas biyopsisinden yapılan Halotan/Kafein kontraktür testi sonucunda şüpheli olanlar, } \\
\text { - Hipertermiye yatkınlığı saptanmış, akrabaların varlığı, } \\
\text { - } \quad \text { Belirgin ve devamlı artan Kreatin kinaz (CK) düzeyi, } \\
\text { Bazı ender görülen kas hastalıklar. }\end{array}$ \\
\hline Komplikasyonlar \\
\hline $\begin{array}{l}\text { - Tanımlanamayan, beklenmeyen taşikardi ve masseter kas spazm/ (genellikle karbondioksit artışını takiben oluşur), } \\
\text { - } \quad \text { Isının yükselmesi ( genellikle geç bulgusudur), } \\
\text { - Respiratuar asidoz ve metabolik asidoz, } \\
\text { - Iskelet kas sertliği, } \\
\text { - Laboratuvar bulgularının anormalliği: kan-koagülasyon profili, elektrolitler, arteryal kan gazı, kreatinin kinaz, ürine- myoglobin. }\end{array}$ \\
\hline Uygulanabilecek Girişimler \\
\hline 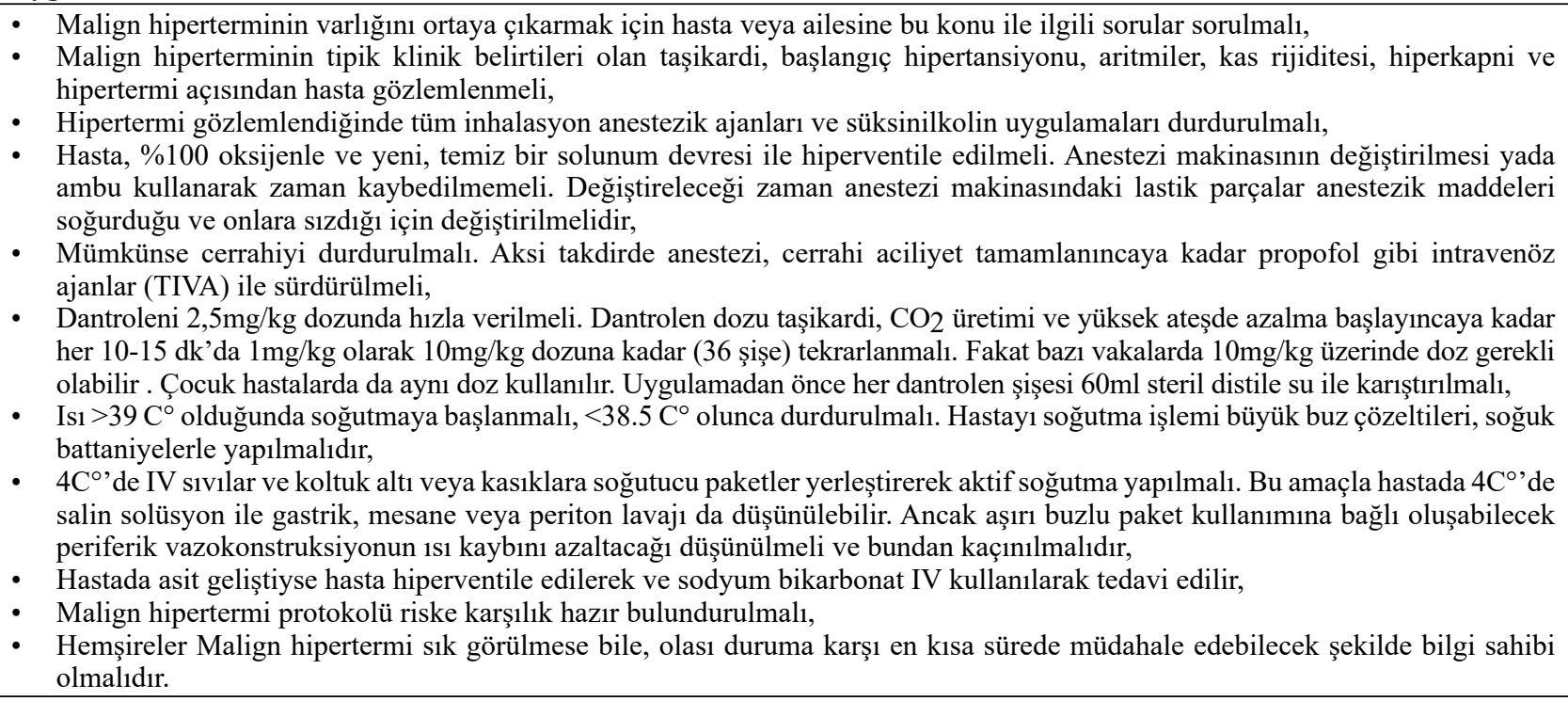 \\
\hline
\end{tabular}

Kaynak: Closs ve ark. 1986; Erickson ve Yount 1991; Hind 1994; Roizen ve ark. 1980; TARD 2015; van Wijk ve Smalhout 1990; Vartiainen ve ark. 1995. 
Tablo 4. Ameliyat Sırası (İntraoperatif) Dönemde Pozisyon Verilmesinde Hemşirenin Rolü

\begin{tabular}{|l|}
\hline \multicolumn{1}{|c|}{ SUPINE (SIRTÜSTÜ) POZISYONU } \\
\hline Kullanılan ameliyatlar \\
\hline - $\quad$ Karın (abdominal), \\
• Karın ve gögüs (abdominotorasik), \\
• $\quad$ Bazı alt ekstremite ameliyatları için kullanılır. \\
\hline Riskler
\end{tabular}

- Oksiput, skapula, torasik vertebra, omuz, sakrum, topuk, iskial tuberositler ve popliteal arter olan basınç ve nekroz gelişimi

- Obez hastalarda abdominal organların ya da hamilelerde fetüsün vena cavaya basınç oluşturması sebebiyle kalbe dönen kan miktarı ve basincinda azalma,

- Brakiyal pleksus, radiyal, ulnar, peroneal ve tibiyal sinir hasarı ve obturator sinir dallarında gerilme,

- Post operatif sirt ve bel ağriları,

- Aşil tendonu yaralanmasına,

- Kalça çıkı̆̆ı ve osteoporotik femurun kırılması.

Uygulanabilecek Girişimler ve Güvenlik Önlemleri

- Ekip işbirliği sedatize hastanın güvenli bir şekilde yatağa alınmasında önemlidir,

- Hastayı ameliyat masasına transfer ederken,

- 1 anestezist ve 1 bakım verici 24 kg'a kadar olan hastaları,

- 1 anestezist ve 2 bakım verici 48 kg'a kadar olan hastaları taşımada görev almalıdır,

- Bir saatin üzerinde sürecek cerrahi işlemlerde basınca bağlı yaralanma riski yüksek olduğu için riskli bölgelerin desteklenmesi önemlidir,

- Bası noktalarına (oksiput, sakrum, skapula vs.) olan basıncı azaltmak için bacaklar omurga ve baş ile aynı hizada düz ve paralel olacak şekilde hasta sırtüstü yatırılır. Ayak bilekleri çaprazlanmaz. Hasta uzun boylu ise ek uzantılar masaya yerleştirilir,

- Aşil tendonu yaralanmasını önlemek için topukların altı destek malzemeleriyle desteklenir ve topukların masadan aşağı sarkması engellenir,

- Başlık ya da simit ile hastanın baş kısmı desteklenerek boyun kaslarının aşırı gerilmesi ve boyuna yapılabilecek aşırı rotasyon önlenir. Bu uygulama aynı zamanda bası noktalarını koruyarak saç kaybını önler,

- Hastanın kolları sinir hasarını önlemek için 90 derece olacak şekilde kol tahtasına yerleştirilir. Eğer kollar hastanın yanına yerleştirilecekse sıkışmamış olduğundan emin olunur,

- Hastanın dirsekleri destek malzemeleri ya da küçük sünger yastıkla desteklenir,

- Hastanın bel eğimi destek malzemeleriyle desteklenerek oluşabilecek sırt gerginliği önlenir,

- Dizdeki bası noktalarını korumak için dizlerin altı küçük sünger yastıklarla desteklenmelidir,

- Dizin hiperekstansiyonunu önlemek için dizlerin $5 \mathrm{~cm}$ yukarısından kemer bağlanır. Cilt ile kemer arasında hiçbir şeyin olmadiğından (örtü vb.) emin olunmalıdır,

- Ayak düşmesi ve plantar fleksiyonu önlenmek için ayak tahtası parmaklara kadar uzatılarak kullanılabilir,

- Obezlerde ve hamilelerde kalbe dönen kan miktarı ve basıncı vena cavadaki basınç nedeniyle azalır. Hastanın sağ tarafına destek yerleştirilerek bu basınç engellenir,

- Dolaşım ve solunum problemi olan hastalar bu pozisyonu tolere edemeyeceği için semi fowler /fowler pozisyon verilir.

TRENDELENBURG (BAŞ AŞAĞI) POZISYONU

Kullanilan ameliyatlar

- Trendelenburg pozisyonu; özellikle pelvis ve alt karın bölgesindeki ameliyatlar ile santral venöz katater takılmasında kullanılır.

Riskler

- Baştan venöz dönüşün azalmasına bağlı görme kaybı, göz içi ve kafa içi basınçta yükselme,

- Organların diyafragmaya olan basısından dolayı kalp sıkışması, kalp rezervleri sıkıntılı hastalarda akut kalp yetmezliği riski,

- Hipovolemiye bağlı hipotansiyon,

- Endotrakeal tüpün içeri kayması ile sol akciğer pozisyonunda bozulma,

- Akciğer volümünde düşme. 
Tablo 4. Ameliyat Sırası (İntraoperatif) Dönemde Pozisyon Verilmesinde Hemşirenin Rolü (Devamı)

\section{Uygulanabilecek Girişimler ve Güvenlik Önlemleri}

- Bu pozisyonda pelvik organlar abdominal bölgeye doğru hareket ettikleri için çok rahat görünürler,

- Hasta önce sırtüstü düz yatırılır. Daha sonra hastanın başı aşağıda olacak şekilde ameliyat masasına 10-45 derece arasında eğim verilir. Diz eklemi ve popliteal alan üzerindeki basınç en az olacak şekilde dizler yerleştirilerek ameliyat masasının diz kısmı kıvrilmalı,

- Hasta güvenliği açısından omuz tutucu askılar brakial pleksus yaralanması engellenecek şekilde bu pozisyonda kullanılır. Brakial pleksus yaralanması omuz altı iyi desteklenmezse görülebilir,

- Kalbin organların diyafragmaya basısı sonucu sıkışması ve akciğer volümünde düşme nedeniyle hasta bu pozisyonda olabildiğince kısa süre tutulmalıdır,

- Hastada bu pozisyondan sırtüstü pozisyona getirilirken hipovolemiye bağlı hipotansiyon gözlemlenebilir. Bu nedenle ani ve hızlı hareketlerden kaçınılarak pozisyon değiştirilmeli ve hasta tekrar normal pozisyona yavaş getirilmelidir,

- Hastanın ayak kısmı ayak tahtası ile desteklenerek hastanın kayması engellenir.

\section{LITOTOMİ POZISYYONU}

\section{Kullanılan ameliyatlar}

- Genellikle jinekolojik amaeliyatlar, vajinal histerektomi, dilatasyon, küretaj, servikal biyopsi, doğum, ürolojik, alt GIS, perine, rektum ameliyatlarda kullanılır,

- Alçak, standart, yüksek,litotomi pozisyonu gibi türleri vardır

\section{Riskler}

- Oksiput, dirsek, lomber/sacral bölgeler, ayak bileği, dizin arka kısmı, ayağın alt kısmında bası,

- Vasküler konjesyon,

- Sirt ağrısıdır,

- Sistemik Hipotansiyon,

- Organların diyafragmaya olan basısından dolayı diafragmatik hareketlerde kısıtlanma,

- Alt ekstremite tendon ve ligament hasarı, kalça çıkı̆̆ı,

- Obturator, femoral, peroneal/ulnar sinir nöropatisi, peroneal sinir hasarı sonucu düşük ayak,

- Posterior tibial sinirin tarsal tünel alanında alanında sıkışması sonucu ayak tabanında yanma ve uyuşukluk,

- Kompartman sendromu.

\section{Uygulanabilecek Girişimler ve Güvenlik Önlemleri}

- Hastaya bu pozisyonu vermeden önce ameliyatın süresine göre troembolitik çoraplar giydirilmelidir,

- Perineal bölgenin görülmesi gereken cerrahi işlemlerde bacaklar kaldırılarak, bacak tutuculara güvenli şekilde yerleştirilir,

- Ameliyat masasının ayak yüksekliği cerrahın isteğine göre ayarlanır,

- Kalçalar 90 dereceden fazla fleksiyona getirilmez,

- Masa kalça bölümünden kırılarak, hastanın bacaklara kadar olan vücut bölümünün masa üstünde kalması sağlanır,

- Hastanın kolları 90 derece olacak şekilde kol tahtalarına yerleştirilir,

- Hastanın ayak parmakları ayak bacak desteklerinin pozisyonu değiştirilirken yaralanmalardan korunur,

- Eğer cerrahi işlem dört saatten uzun sürecekse hastanın bacakları her iki saatte bir deri ve sinir yaralanması, kompartman sendromu vb. riskler yönünden değerlendirilerek bu riskler azaltılmaya çalışılır.

\section{YAN (LATERAL DEKÜBITT/SIMS ) POZISYONU}

\section{Kullanılan ameliyatlar}

- Göğüs, omurga, kalp, böbrek ve üst üreter ameliyatlarında, anterior torasik distektomi ve füzyonlarda, spinal korda elektrot yerleştirilmelerinde, ağrı tedavisi için intratekal pompa yerleştirilmesinde sık kullanılır.

\section{Riskler}

- Vücut ağırlığının bir omuz üzerinde olmasına bağlı brakial pleksus zedelenmesi, supraskapular, ulnar, tibial ve sakral sinir hasarı,

- Kolun venöz akımında bozulma,

- Kulak, burun, göz, iliak başı, akromiyal çıkıntılar, büyük torakanterler ve erkek genital organlarına bası,

- Omurgada dönme,

- Akciğer volümünde değişme. 
Tablo 4. Ameliyat Sırası (İntraoperatif) Dönemde Pozisyon Verilmesinde Hemşirenin Rolü (Devamı)

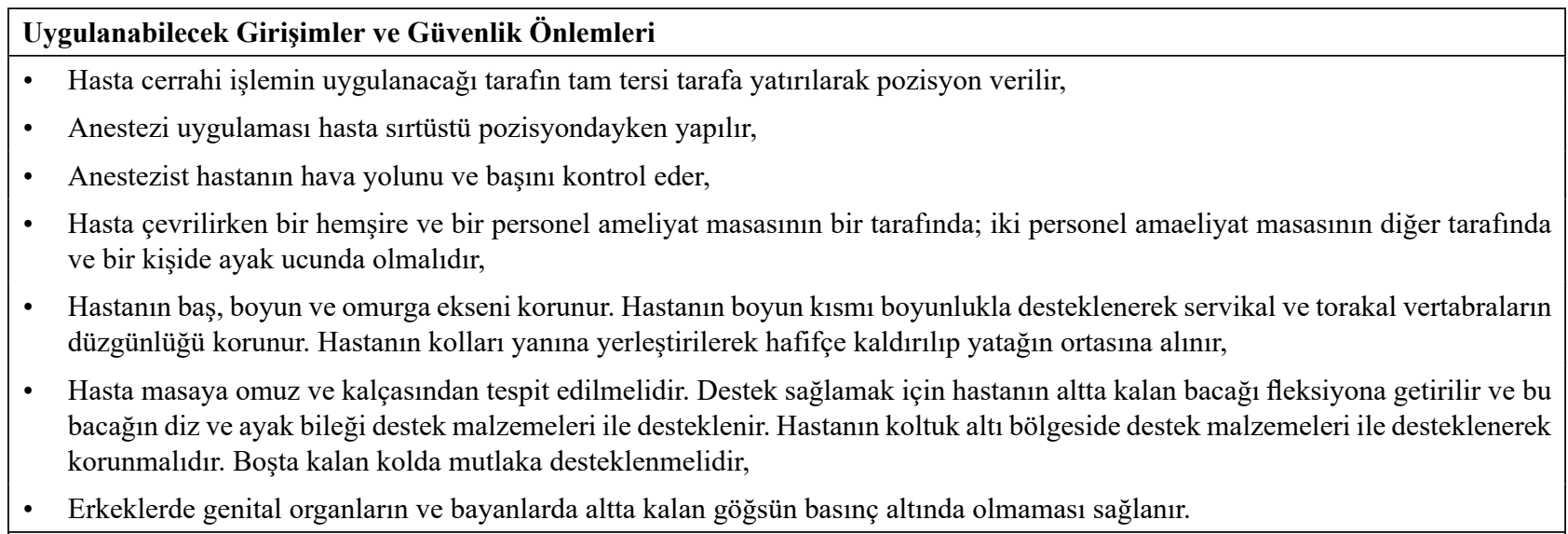

SEMI FOWLER (OTURMA) POZISYONU

\section{Kullanılan ameliyatlar}

- Bu pozisyon servikal ve vertikal omurga ameliyatları, posterior vertikal laminektomi, posterior spinal tümörlerin giderilmesi, posterior fossa kraniektomi, kulak, beyin cerrahinin arka çukuru ve arka boyun ameliyatlarında ve pelvis drenajını sağlamada kullanılır.

\section{Riskler}

- Venöz basıncın azalması nedeniyle venöz hava embolisi,

- Subatmosferik basınç, serebral iskemi, hipotansiyon,

- Oksiput,skapula, dizin arka kısmı, koksise bası,

- Siyatik sinir gerilmesi sonucu ayak düşmesi,

- Supraskapular, ulnar, siyatik, parenoal, anterior spinal sinir hasraları.

Uygulanabilecek Girişimler ve Güvenlik Önlemleri

- Hastanın sırtı hafif fleksiyonda yaklaşık 90 derece kaldırılır ve bacaklar aşağıdadır,

- Hasta sırtüstü pozisyonda iken yatağın baş tarafı kaldırılıp, ayak tarafı indirilerek hasta yavaşça semi fowler pozisyonuna getirilir,

- Basınçlı çorap anestezi uygulandıktan sonra giydirilir ve ayak düşmesini önlemek için ayak tahtası kullanılır,

- Kafa tutucu araç gereçler kranial cerrahi uygulamaları sırasında başın pozisyonu için kullanılır,

- Hastanın baş, gögüs ve gövde ekseninin bozulmaması sağlanır,

- Basınç noktalarına dikkat edilerek erkeklerde genital organların bacak arasına sıkışmamasına dikkat edilir.

KRASKE (JACKKNIFE) POZISSYONU

Kullanılan ameliyatlar

- Rektum ve çevresine ait bölgelerdeki (pilonidal sinüs, hemoroidektomi gibi) ameliyatlar için kullanılır.

Riskler

- Temporal, akromion, klavikula, göz, burun, kulak, çene, uyluk, dizler, ayak kenarları, parmaklar, iliak kemik çıkıntılarına, kadınlarda göğüs ve erkeklerde genital organlara bası.

Uygulanabilecek Girişimler ve Güvenlik Önlemleri

- Hasta supine pozisyondayken anestezi verilir ve anestezi sonrası hasta çevrilerek karın üzerine yatırılarak baş yana çevrilir ve simit veya yastıkla desteklenir,

- Genel anestezi verilecek hastalarda göğüs altına destek malzemeleri konularak göğüs kaldırılır,

- Avuç içi aşağıda, dirseklerden bükülü şekilde kollar kol masalarında olmalıdır,

- Masanın bacak bölümüne istenilen eğim verilerek kalçanın yüksekte kalması sağlanır,

- Ayaklar destek malzemeleriyle desteklenerek, emniyet kemeri diz altlarından bağlanır. 
Tablo 4. Ameliyat Sırası (İntraoperatif) Dönemde Pozisyon Verilmesinde Hemşirenin Rolü (Devamı)

\begin{tabular}{|c|}
\hline PRONE (YÜZÜSTÜ) POZİSYON \\
\hline \\
\hline $\begin{array}{l}\text { - Omurga,cerrahisi, lumbar laminektomi, spinal füzyon, distektomi, servikal herni, anüs, rektum ve perine cerrahisinde, pilonidal } \\
\text { sinüs; açık hemoroidektomi, fistülotomi, sigmoidoskopi, spinal kolon gibi ameliyatlarda tercih edilir. }\end{array}$ \\
\hline Riskler \\
\hline 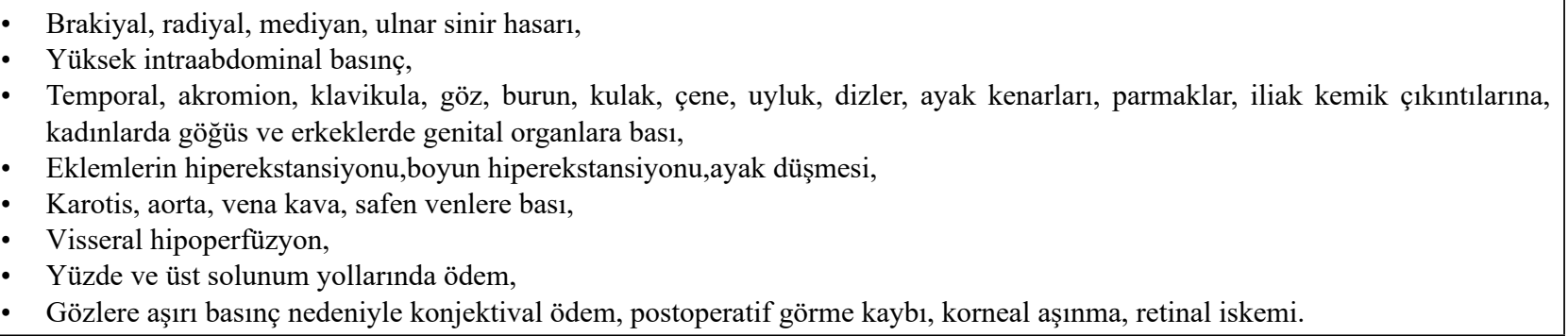 \\
\hline Uygulanabilecek Girişimler ve Güvenlik Önlemleri \\
\hline 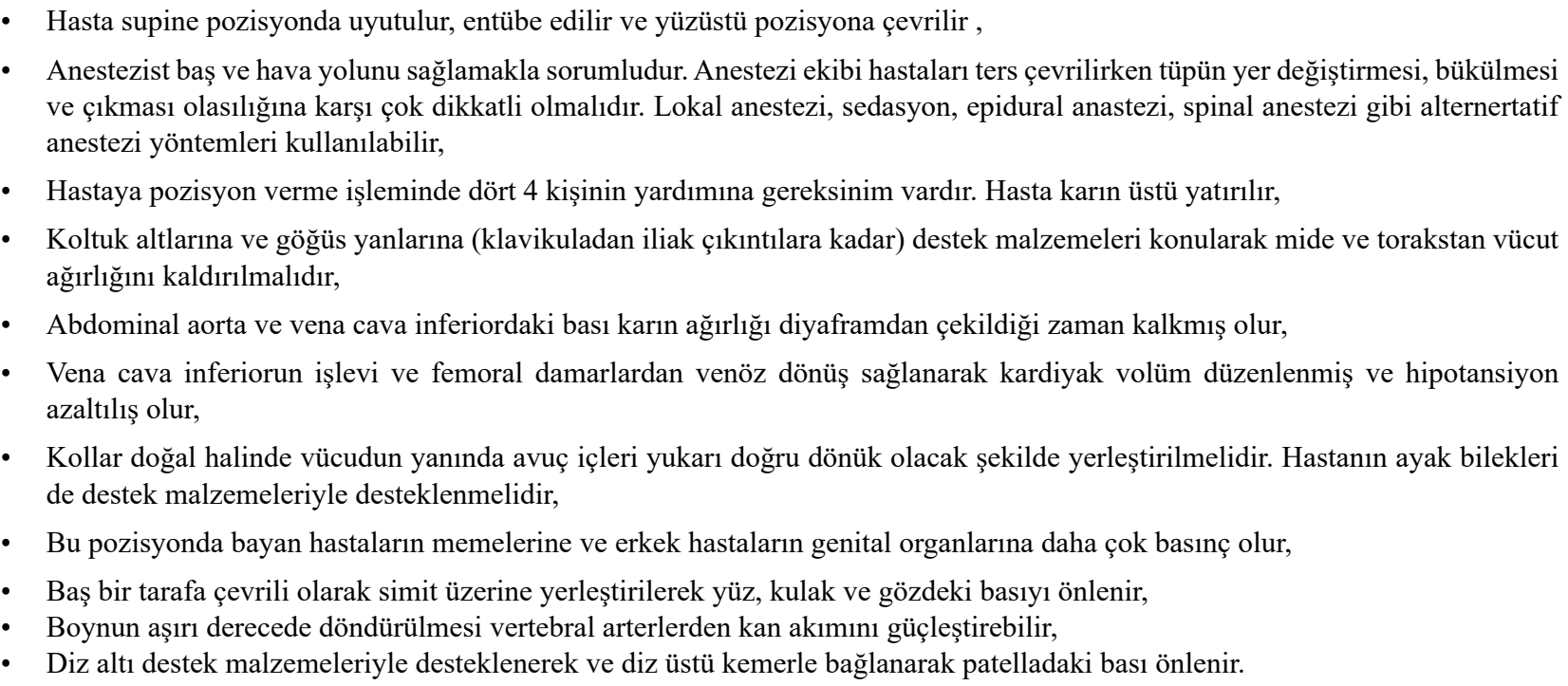 \\
\hline
\end{tabular}

Kaynak: Ferrara 2007; Heizentrot 2007; Kanan 2007; Lopes 2010; O’Connell 2006; Sharon 2010; Warner 2000; Winfree 2005. 
Tablo 5. Ameliyat Sırası (İntraoperatif) Dönemde Bilgi Vermede Hemşirenin Rolü

\section{BİLGİ VERME}

- Hemşireliğin değişen, gelişen çağdaş rollerinden biri de eğitici rolüdür. Temel hasta haklarından biri olarak kabul edilen "bilgilendirme hakkı" kapsamında, hemşire; hekim, diyetisyen, fizyoterapist v.b. gibi diğer sağlık profesyonelleri ile ortak bir tutum içinde olmalı; bakım girişimlerine yönelik ameliyat öncesi, sırası ve sonrasında hasta ve ailesini, gereksinimleri doğrultusunda bilgilendirmeli ya da eğitmeli; onları, öğrenmek istedikleri konulara ilişskin soru sorması için cesaretlendirmelidir,

- Komplikasyon olasılığı yüksek cerrahi girişim deneyimleyecek (acil ya da planlı) hastalar, ameliyat sonrası hastalağın seyri ve olası komplikasyonlara ilişkin kaygı düzeyleri yüksek olduğu için, bilgilenmeye ve öğrenmeye daha fazla gereksinim duyurlar. Ameliyat öncesi ve sırası dönemde bilgi eksikliği hastanın kaygı düzeyini, fiziksel ve psikolojik komplikasyon gelişme olasılığını arttırmaktadır,

- Ameliyat öncesi, sırası ve sonrası dönemlerde hasta ve hasta yakınlarının bilgilendirilmesi bir ekip işi olmakla birlikte; hemşirelerin, hastaya en yakın ve en uzun süre bakım veren sağlık profesyonelleri olarak, bilgilendirmek için iyi bir konumda oldukları yadsınamaz. Hastaların karar verme sürecine katılabilmeleri için hasta ve ailesine yeterli bilginin verilmesi önemlidir,

- Ameliyat sırası dönemde hastaya kaygısını arttırmayacak şekilde ameliyatın içeriği, olası komplikasyonlar ve hastanın kendine yardım için ne yapabileceği gibi konularda açıklama yapılmalıdır,

- Hastaya çok bilgi vermek de hiç bilgi vermemek de kaygısını arttırır. Bu nedenle, hastanın gereksindiği kadar bilginin verilmesi ancak bunun hastanın kendisini bilgiyi almaya hazır hissettiği zaman yapılması önemlidir. Hastaya"ne söylendiği” kadar "nasıl söylendiği” de onemlidir.

Kaynak: Brown 1990; Carr 1990; Cason 1996; Chew 1998; Comey 1992; Dennis 1987; Eyi, Kanan, Akyolcu, Akın, Acaroğlu 2016; Hankela ve Kiikkala 1996; Kelly1994; Williams 1993; Yardakçı 2004.

Tablo 6. Ameliyat Sırası (İntraoperatif) Dönemde Hastaya Psikolojik Destek Olmada Hemşirenin Rolü

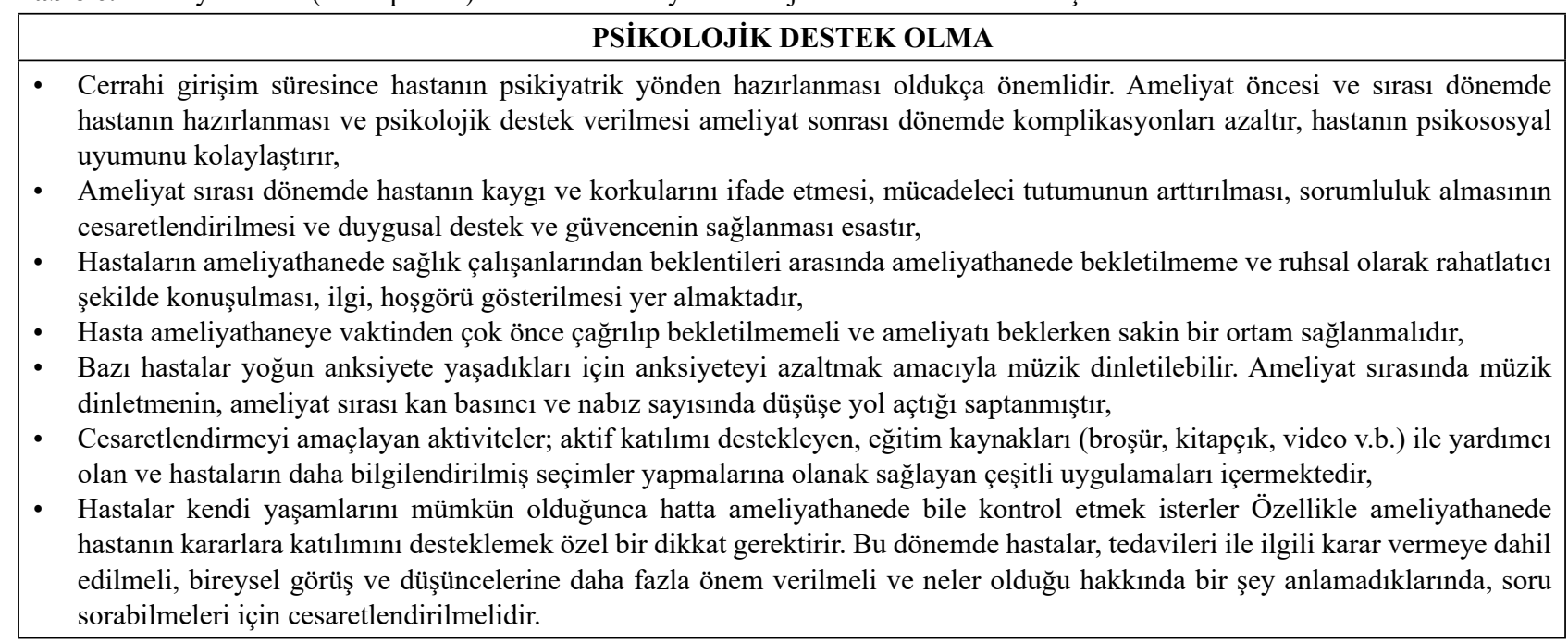

Kaynak: Bardwell 2004; Cunnigham 1997; Dennis 1987; Eyi ve ark. 2016; Hankela ve Kiikkala 1996; Harper-Petersen 1988; Kanan 1991; Kelly1994; Leinonen, Leino-Kilpi ve Jouko 1996; Narred 2000; Özkan 2005; Varol ve Özbayır 2000 ; Williams 1993. 
Tablo 7: Ameliyat Sırası (İntraoperatif) Dönemde Güvenli Çevrenin Sağlanmasında Hemşirenin Rolü

\section{HASTA KIMLIİĞINİ DOĞRU TANIMLAMA}

- Ameliyathaneye girişinden itibaren cerrahi güvenlik kontrol listelerini ve hasta için tanıtıcı materyallerin (bileklik, kol bandı, yaka kartı gibi) kullanılması ve hastaya ismi ile hitap edilmesi gerekir,

- Hasta ameliyathaneye geldiğinde hastanın adı, soyadı, protokol numarası ve doğum tarihi bilgilerinden en az iki tanımlayıcının kullanılması gerekir,

- Hastanın ameliyathaneye transferinden önce (ilaç uygulamaları, kan ve kanürünlerinin temini, tüm tetkikler gibi) ve ameliyathanede uygulanacak tüm girişimlerden önce (anestezi uygulaması, yapılacak ameliyatın adı ve cerrahi tarafın işaretlenmesi gibi) hasta kimliğinin kontrolü şarttır,

- Hastaya ait tüm bilgiler servisten ameliyathaneye, ameliyathaneden servise nakiller sırasında, ameliyatta ekip değişimi esnasında uygun iletişim kurularak mutlaka yazılı olarak iletilmelidir,

- Sözel/telefon direktiflerinde ortak dil ve standart kısaltmalar kullanılarak ilgili politika ve yöntemler belirlenmelidir,

- Cerrahi girişim yapılacak taraf bilgisi ameliyat hazırlık formuna hemşire ve cerrah tarafından yazılarak, klinikten ayrılmadan önce ilgili cerrah hastanın cerrahi girişim yapılacak tarafını işaretlemeli ve ameliyathane içerisinde yine taraf doğrulaması yapilmalidir.

\section{EKIPPTE İLETIŞİM EKSİKLIĞİí ENGELLEME}

- Ameliyathane ortamında ekipteki iletişim bozuklukları cerrahi gecikmelere, hasta güvenliğinde tehdide, personelin üretkenliğini ve karar verme mekanizmalarını etkileyerek moral ve motivasyonunda bozulmalara, verimlilikte azalmaya yol açarak ciddi hatalarla güvensiz bir ameliyathane ortamı oluşturur,

- Dünya Sağlık Örgütü Cerrahi Güvenlik Kontrol Listesindeki etkili iletişime yönelik kontrol listeleri ameliyathane ekip üyeleri arasında kullanıldığında hatalar en aza inmekte, hasta sonuçları iyileşmekte, iletişim süreci basitleşmektedir,

- Ameliyathanede ekip iletişiminde yaşanan sorunlar en sık yanlış taraf cerrahilerine neden olmaktadır,

- Ekip iletişimini geliştirmek için cerrahi ekibin sabırlı ve anlayışlı olması, ekip ruhu içinde çalışması gerekmektedir,

- Hataların önlenmesi için, sözel olarak verilen hasta bilgileri ve rapor sonuçlarının önce not edilmesi, okunması ve tekrarlanması gerekmektedir,

- Ameliyathanede hemşireleri ameliyathane ekibi arasında güvenli ve etkili iletişimi oluşturmada anahtar role sahiptir. Ameliyathanede döngünün kapanışı olarak da bilinen sözleri tekrarlamak/ tekrar duymak söylenenin anlaşıldığını göstermek için kullanılır,

- Ameliyathane lider pozisyonundaki kişiler personeli, olumsuz sonuçları ve durumları hakkında konuşmaları ve işbirliği konusunda teşvik ederek kendilerini güvende hissetmelerine yardımcı olmalıdır,

- Ameliyathane ortamında; açlık, yorgunluk gibi fiziksel dikkat dağıtıcılar ile sözel veya sözel olmayan iletişim kaynaklı psikolojik bozulmalar ve gürültü ekip üyelerinin birbirini anlamasını zorlaştırarak arka planda olumsuz sonuçlara yol açabilir. Bu nedenle hatalı bir şey olduğunda ekip üyeleri anlasa bile korktuğu için konuşmayabilir,

- Ekip üyelerinin endişe duydukları konu hakkında konuşmamaları ameliyathanelerde hasta güvenliğini tehlikeye sokabileceği için açık bir iletişimin ekip üyeleri arasında olması şarttır.

\section{İLAÇ UYGULAMA HATALARINI ÖNLEME}

- Ameliyathanelerde ilaç uygulama hatalarının sıklıkla,

- İlaç uygulanmasından önce hastanın alerjilerini sorgulamama ve kaydetmeme,

- Sözel istemlerin yazılı hale dönüştürülmemesi,

- Benzer isimleri ve etiketleri olan ilaçların uygulama sırasında karıştırılması,

- İlaçların yanlış sulandırılması,

- Enjektöre çekilen ilaçların ve ilaç bölmelerinin etiketlenmemesi sonucunda yanlış ilaçların uygulanması

- Eksik/yetersiz kayıt sisteminden kaynaklandığını bilin.

- İlaç uygulama hatalarını önlemek için öncelikle,

- İlaç, doz, yol, hasta ve zamanı içeren beş doğru ilkesine uyun

- Uygulanan ilaçları mutlaka kaydedin, alerjiye neden olan reçeteli/reçetesiz ilaçları sorgulayın,

- Yüksek riskli ilaçların doğru etiketlenip depolanabileceği sistemin geliştirilmesine ve ayrı saklanmasına yardımcı olun.

\section{ENFEKSIYYON KONTROLÜ}

- Ameliyathanelerde enfeksiyon kontrolü; yanlış/uygun olmayan malzemenin kullanılması önlenerek, tıbbi cihaz ve ekipmanın bakımı ve kalibrasyonları yapılarak, sarf malzemelerinin son kullanma tarihi, sterilizasyon süreleri ve uygunluğu kontrol edilerek, uygun sterilizasyon ve dezenfeksiyon yöntemleri ile enfeksiyon kontrol prosedürleri belirlenerek ve personel eğitilerek sağlanabilir. 
Tablo 7: Ameliyat Sırası (İntraoperatif) Dönemde Güvenli Çevrenin Sağlanmasında Hemşirenin Rolü (Devamı)

\section{HASTA DÜŞMELERİ}

- Ameliyathanede hasta düşmeleri,

- Taşımadan sorumlu personelin dikkatsizliği,

- Hemşirenin eşlik etmemesi,

- Hastanın anestezinin etkisinde olması gibi nedenlerden kaynaklanmaktadır.

- Bu nedenle, ameliyathane sedyeleri ve ameliyat masalarının,

- Kenarlıklı ve emniyet kilitli olmasının sağlanması,

- Hastanın taşınmasından sorumlu personelin konuyla ilgili eğitim alması,

- Islak zemin kontrolünün yapılmas1,

- İyi aydınlatmanın düşmelerin engellenmesinde önemli bir girişim olduğunun unutulmaması gibi noktalara dikkat edilmelidir.

\section{CERRAHI ORTAMA BAĞLI YANIKLAR}

- Koter cihazı ve lazere bağlı yanıkların önlenmesi için,

- Hastanın tüm takılarının çıkartılması gerekir,

Koter plağının doğru boyda olmasına dikkat edilmelidir,

- Koter plağının yerleştirileceği vücut bölümünün doku bütünlüğü değerlendirilerek yerleştirileceği en uygun alan seçilmelidir,

- Bu alan ameliyat bölgesine oldukça yakın, kalın kas gruplarının üzerinde, tüysüz, dolaşımı iyi olan bir alan olmalıdır,

Plak iyi temas edecek şekilde yerleştirilmelidir,

Elektrikli cihazların düzenli kontrol, bakım ve onarımı sağlanarak kullanma kılavuzlarına uygun kullanılmalıdır.

\section{YÜKSEK RİSKLİ HASTALARIN BELİRLENMEMESI}

- Ameliyathanede yüksek riskli hasta grubunu;

- Yetmiş yaş ve üzeri hastalar,

- Kronik, bulaşıcı ve akıl sağlı̆̆ bozuk olanlar; bilinci kapalı,

- Bağışıklık sistemi yetersizliği olanlar,

- Diyaliz uygulanan hastalar ve çocuk hastalar oluşturur,

- Ameliyathane ortamına uyum sağlamada bu hasta grubu güçlük çekebileceğinden, bu hasta grubu bakımı için ortak politika geliştirilip, ameliyathane çalışanlarının sürekli eğitiminin sağlanması önemlidir.

\section{GÜVENLI TRANSFÜZYON}

- Cerrahi girişimler, risk derecelerine, işlem büyüklüklerine ve ameliyat bölgesine göre kan kaybına neden olmaktadır,

- Bu nedenle kan transfüzyonu uygulanacak hastalar için elde edilen kanın,

- Uygun koşullarda saklandığından,

- Mikrobiyolojik testlerinin standartlara uygun olarak ve güvenilir test malzemesiyle yapıldığından emin olunmalıdır,

- Transfüzyon kurallarına uyulmalıdır.

\section{YANLIS TARAF CERRAHISINIIN ÖNLENMESİ}

- Ameliyat öncesi dönemde hasta bilgilerinin doğru tanımlanması yanlış taraf cerrahisi riskinin en aza indirilmesi için önemlidir. Buna yönelik kurumlar tarafindan,

- Ameliyat öncesi doğrulama sürecinde; kurum tarafından kullanılan kayıt formları, ameliyat için alınmış hasta onamı, gerekli olabilecek kan ürünleri, implant veya özel araçların hazır bulunması sağlanmalıdır,

- Hasta uyanık ve bilinçli olduğu dönemde hastanın da katılımı sağlanarak insizyonun yapılacağı cerrahi alan işaretlenmeli ve işaretlenirken silik olmayan belirgin işaret konmalı, 'X" gibi karışıklığa neden olabilecek işaretler ve yapışkan kullanılmamalıdır,

- İşaret cerrahi girişim alanına yakın olmalı fakat cilt hazırlığı ve cerrahi sargıların görünmesini engellememelidir,

- İşaretlemede kullanılan kalem cerrahi alanda kontaminasyona neden olmamaktadır,

- El, ayak parmakları ve lezyonlar gibi çoklu yatay yapılarda veya lomber, torokal ve servikal omurlar gibi çoklu düzeylerde en uygun ve en yakın bölge işaretlenmelidir,

- Sezaryan bölgesi, kalp cerrahisi gibi tek organ vakalarında, cerrahi işlem planlanan açık yara ve lezyonlarda, acil girişimlerde, kalıcı iz bırakabileceğinden dolayı bebeklerde işaretleme yapılmaz,

- Ameliyathanelerde yanlış taraf cerrahisinin önlenmesi için; bu konuda çalışan kuruluş ve derneklerin (AORN, JCAHO DSÖ) geliştirdikleri kontrol listeleri gibi standart listeler kullanılarak doğru hasta, taraf ve bölge, yapılacak işlem, doğru hasta pozisyonu, implant veya diğer özel araçların gerekliliği tanımlanarak kaydedilmelidir.

\section{BASINÇ YARALANMALARI}

- Farklı cerrahi girişimler için uygun pozisyonları ve buna bağlı olarak gelişebilecek fizyolojik değişimlerin cerrahi ekip tarafından bilinmesi önemlidir,

- Ameliyat olan her hasta bası yarası oluşumuna karşın risk grubunda değerlendirilmelidir,

- Pozisyon, solunum ve dolaşımın yeterli olmasına izin verecek şekilde olmalıdır,

- Masa tespit bantları/ kemerleri çok sıkı bağlanmamalı, sinirler, kaslar ve kemik çıkıntıları silikon yastık gibi pozisyon destek ekipmanlarıyla uygun şekilde desteklenmelidir,

- Ayrıca, kol ve bacaklar masadan sarkmamalı, tüm beden ağırlığı tek bir noktaya verilmemelidir.

Kaynak: Aslan ve Ünal 2005; Demir 2003; Demir ve Dramal1 2005; Erdil 2001; Göçmen 2004; Kanan 2012. 
Ameliyat sırası dönemde hasta gereksinimlerini belirleyerek, hemşirelik süreci çerçevesinde hasta hedeflerini ve sonuçlarını düzenleyen risk yönetimini ele almak, hemşirelik bakımını uygulamak, sonuçta kaliteli bakıma ve hasta memnuniyetine ulaşmak için bir yol gösterici olabilir.

\section{KAYNAKLAR}

Aslan, Ö., Ünal, Ç. (2005). Cerrahi yoğun bakım ünitesinde parenteral ilaç uygulama hataları. Gülhane Tıp Dergisi, 47(3): 175-178.

Association of Surgical Technologist (AST) (2015). AST standards of practice form a intenance of normotermia in the periopertive patient. 1-26, http://www.ast.org/uploadedFiles/Main_Site/Content/ About_Us/SOP_For_Normothermia.pdf (26.12.2016).

Bardwell, W. A. ve ark. (2004). Healt- related quality of life in women previously treat for early-stage breast cancer. Psychooncology,13: 595-604.

Brown, S. M. (1990a). Quantitative measurement of anxiety in patients undergoing surgery for renal calculus disease. Journal of Advanced Nursing, 15: 962-970.

Burns, S. M., Wojnakowski, M., Piotrowski, K., Caraffa, G. (2009). Unintentional hypothermia: Implications for perianesthesia nurses. J Perianesth Nurs, 24(3): 167-173.

Carr E. C. J. (1990). Postoperative pain: Patients' expectations and experiences. $J$ Adv Nurs, 15(1): 89-100.

Cason C. L., Seidel, S. L., Bushmiaer, M. (1996). Recovery from laparoscopic cholecystectomy procedures. AORN Journal, 63: 1099-1116.

Chew, S. T., Tan, T., Tan, S. S., Ip-Yang, P. C. (1998). Survey of patients' knowledge of anaesthesia and perioperative care. Singapore Medical Journal, 39(9): 399-402.

Closs S. J., Macdonald J. A., Hawthorn P. J. (1986). Factors affecting perioperative body temperature. $J$ Adv Nurs. 11(6): 739-744.

Cohen, S. (2007). Critical Thinking in The Perioperative Department: Skills to Assess. 1st ed., Analyze, and Act, HCPro, Inc., USA.

Comey, R., Everett, H., Howells, A. Crowther, M. (1992). The care of patient undergoing surgery for gynaecological cancer the need for information emotional support and counselling. J Adv Nurs, 17: $667-671$.

Cunnigham, M. F. ve ark. (1997). Introducing a music program in the perioperative area. AORN Journal, 66(4): 674-682.

Demir, F., Dramalı, A. (2005). Ameliyathanelerde ilaç hataları. Ulusal Cerrahi Kongresi Cerrahi Hemşireliği Seksiyonu Panel ve Bildirileri Kongre Kitabl, Ege Üniversitesi Basımevi, İzmir,165-177.
Demir, F. (2003). Cerrahi ünitelerinde enfeksiyonlardan korunma yöntemleri. 4. Ulusal Cerrahi ve Ameliyathane Hemşireliği Kongre Kitabl, Ege Üniversitesi Basımevi, İzmir, 13-42.

Dennis, K. E. (1987). Dimensions of client control. Nurs Res, 36: 151-156.

Ellis-Stoll, C. C., Anderson, C., Cantu, L. G., Englert, J., Carlile, W. E. (1996). Effect of continuously warmed IV fluids on intraoperative hypothermia. AORN Journal, 63: 599-606.

Erdil, F. (2001). Cerrahi hemşireliği. Erdil, F., Elbaş, N. Ö. (Eds.). Cerrahi Hastalıkları Hemşireliği. 4. basım, Aydoğdu Ofset, Ankara, 97-136.

Erickson, R. S., Yount, S. T. (1991). Comparison of tympanic and oral temperatures in surgical patients. Nurs Res, 40(2): 90-93.

Eyi, S., Kanan, N., Akyolcu, N., Akın, M. L., Acaroğlu, R. (2016). Ameliyat sırasında uygulanan hemşirelik bakımının hastalar tarafından değerlendirilmesi. TAF Prev Med Bull, 15(2): 159-170.

Ferrara, D. L. (2007). Neurosurgery. Rothroch, J. C. (Ed.). Alexander's Care of The Patient in Surgery. 13th ed., Mosby/ Elsevier, St. Louis, Canada, 799-862.

Göçmen, Z. (2004). Ameliyathane hemşirelerinin ameliyathane hemşireliği oryantasyon programı içeriğine ilişkin görüşleri. C. $\ddot{U}$. Hemşirelik Yüksek Okulu Dergisi, 8(1): 12-24.

Hankela, S. ve Kiikkala, I. (1996). Intraoperative nursing care as experienced by surgical patients. AORN Journal, 63: 435-442.

Harper-Petersen, M. B. (1988). Measuring patient satisfaction: Collecting useful data. Journal of Nursing Quality Assurance, 2(3): 25-35.

Heidenreich, T., Giuffre, M., Doorley, J. (1992). Temperature and temperature measurement after induced hypothermia. Nurs Res, 41: 296-300.

Heidenreich T., Giuffre, M. (1990). Post-operative temperature measurement. Nurs Res, 39: 153-155.

Heizentrot, H. P. A. (2007). Positioning the patient for surgery. Rothroch, J. C. (Ed.). Alexander's, Care of The Patient in Surgery. 13th ed., Mosby/ Elsevier, St. Louis, Canada, 130-157.

Hind, M. (1994). An investigation into factors that affect oesophageal temperature during abdominal surgery. J Adv Nurs, 19(3): 457-464.

Kanan N, Atilla T. (2002). Ameliyat hemşireliği oryantasyon programlarının süresi ne olmalı? Hemşirelik Forumu Dergisi, 5(34):13-18.

Kanan, N. (2012). Ameliyat Sırası Hemşirelik Bakımı. Aksoy, G., Kanan, N., Akyolcu, N. (Eds.). Cerrahi Hemşireliği I. 1. basım, Nobel Tip Kitabevi, İstanbul, 306-307. 
Kanan, N. (1991). Ameliyathane hemşireliğinin psikolojik yönleri. Hemşirelik Bülteni Dergisi, 5(21): 51-56.

Kanan, N. (2007). Hastaya Pozisyon Verme. III. Nöroşirurji Hemşireliği Kongresi, 20-24 Nisan, Antalya.

Kaymakçı, Ş. (2005). Ameliyathanede görev yetki ve sorumluluklar. Cerrahi ve Ameliyathane Hemşireleri Derneği Bülteni, 5(1): 3-7.

Kelly, M. P. (1994). Patients' decision making in major surgery: The case of total colectomy. J Adv Nurs, 19: 1168- 1177.

Laden, C. S. (1999). Concepts basic to perioperative nursing. Meeker, M. H., Rothrock, J. C. (Eds.). Care of the Patient in Surgery. 10 th. ed., Mosby, St Louis, 3-4.

Leinonen, T., Leino-Kilpi, H., Jouko, K. (1996). The quality of untraoperative nursing care: The patient's perspective. $J$ Adv Nurs, 24: 843-852.

Lopes, C.M. M., Galvão, C. M. (2010). Surgical positioning: Evidence for nursing care. Rev. Latino-Am. Enfermagem, 18(2): $287-$ 294.

McGarvey, H. E., Chambers, G. A. M., Boore, R. P. J. (2000). Development and definetion of the role of the operating department nurse: A review. $J$ Adv Nurs, 32(5): 1092-1100.

Narred, C. L. (2000). Minimizing preoperative anxiety with alternative caring. AORN, 72(5): 838-843.

National Institute for Health and Care Excellence (NIH) (2008). Inadvertent perioperative hypothermia: The management of inadvertent perioperative hypothermia in adults, https://www.nice.org. uk/guidance/cg65/chapter/introduction. (26.12.2016).

Nicolette, L. (1996). The perioperative nursing environment. Groah-Linda, K. (Ed.). Perioperative Nursing. 3th ed., Appleton \& Lange, Stamford, Conn USA, 1-83.

O'Connell, P. (2006). Positioning impact on the surgical patient. Nurs Clin North Am,1(3): 173-192.

Özbayır, T. (2010). Ameliyat Dönemi Bakım. Karadakovan, A., Eti-Aslan, F. (Eds.). Dahili ve Cerrahi Hastalıklarda Bakım. Adana Nobel Tip Kitapevi, 309-344.

Özkan, S. (2005). Meme kanserli hastaya psikolojik yaklaşım. VIII. Ulusal Meme Hastalıkları Kongresi, 21-24 Eylül, İstanbul.
Roizen, M. F., Sohn Y. J., L'Hommedieu, C. S., Wylie, E. J., Ota, M. K. (1980). Operating room temperature prior to surgical draping: Effect on patient temperature in recovery room. Anesth Analg, 59: 852-855.

Sharon, A, Wicklin, V. (2010). Safely positioning the surgical patient. Aorn Journal, 92(6): 703-706.

Türk Anesteziyoloji ve Reanimasyon Derneği (TARD) (2013). İstenmeyen perioperatif hipoterminin önlenmesi rehberi. Turk J Anaesth Reanim, 41: 188-190.

Türk Anesteziyoloji ve Reanimasyon Derneği (TARD) (2015). Malign Hipertermi Krizini Tanıma ve Yönetim Kılavuzu 1-12, https://www. tard.org.tr/assets/kilavuzlar/malignhipetermi.pdf. (26.12.2016).

Uludoğan, S. (2010). Ameliyathane hemşirelerinin yönetsel sorunlarının incelenmesi. Yüksek Lisans Tezi, Marmara Üniversiyesi Sağlık Bilimleri Enstitüsü, İstanbul.

van Wijk, M. G. F., Smalhout, B. A. (1990). Postoperative analysis of the patient's view of anaesthesia in a Netherlands' teaching hospital. Anaesthesia, 45(8): 679-682.

Varol, Ş., Özbayır, T. (2000). Sedatif müziğin preoperatif kaygı düzeyine intraoperatif kan basıncı ve nabız parametrelerine etkisi. Hemşirelik Forumu Dergisi, Ameliyathane Özel Sayıs1, 3(6): 15-18.

Vartiainen, H., Vuorio, O., Halonen, P., Hakola, P. (1995). The patients' opinions about curative factors in involuntarily treatment. Acta Psychiatr Scand, 91(3): 163-166.

Warner, M. A., Warner, D. O., Harper, C. M., Schroeder, D. R. (2000). Lower extremity neuropathies associated with litotomy positions. Anesthesiolgy, 93(4): 938-942.

Williams, O. A. (1993). Patient knowledge of operative care. $J R$ Soc Med, 86: 328-331.

Winfree, C. J., Kline, D. G. (2005). Intraoperative positioning nerve injuries. Surg Neurol, 63: 5-18.

Yardakçı, R., Akyolcu, N. (2004). Ameliyat öncesi dönemde yapılan hasta ziyaretlerinin hastanın anksiyete düzeyine etkisi. Hemşirelikte Araştırma Geliştirme Dergisi, 6(1,2): 7-14.

Yüksel, S., Altun-Uğraş, G. (2016). Cerrahi hastasında hipotermi gelişimini önlemede hemşirenin rolü. Mersin Univ Saglık Bilim Dergisi, 9(2): 113-121. 